\title{
Knowledge, attitude and practice regarding leprosy and tuberculosis in Bangladesh
}

\author{
RICHARD P. CROFT \& ROSEMARY A. CROFT \\ The Leprosy Mission, Danish Bangladesh Leprosy Mission, PO Box 3, \\ $P O$ and Dt Nilphamari 5300, Bangladesh
}

Accepted for publication 20 September 1998

\begin{abstract}
Summary A small survey was carried out in two areas of northern Bangladesh to assess and compare the level of knowledge, attitude and practice towards leprosy and tuberculosis (TB) among two communities that differed widely in the amount of health education received about these diseases. The results indicate that without a health education programme, levels of knowledge about the cause and treatability of the diseases are poor, worse for leprosy than TB, with correspondingly negative attitudes. Only $16 \%$ of the respondents in the 'uninformed' area mentioned 'skin patch' in a question about what they knew about leprosy; and only $44 \%$ mentioned 'cough' as a symptom of TB. In the area that had received health education, 90\% mentioned, respectively, 'skin patch' and 'cough'. Seventy-eight percent of the respondents would not buy goods from a shopkeeper known to have leprosy, $76 \%$ if he had TB in the uninformed area; but in the community who had received health education the proportions were reversed, with three-quarters agreeing to purchase from a diseased shopkeeper. The implications of these findings for the DBLM and National Heaith Education programmes are discussed.
\end{abstract}

\section{Introduction}

Leprosy and tuberculosis (TB) are considered to be major public health problems in Bangladesh, and both are the subject of very active control programmes in which the Government of Bangladesh (GoB) and Non-Government Organisations (NGOs) are sharing resources to achieve the aim of disease control. Both the GoB and NGOs are involved in health education campaigns to the population. Since 1993, the GoB Leprosy and TB Control Services have been involved in IEC (Information, Education and Communication) activities with the general public through radio, TV, newspaper advertising, advocacy meetings, handbills, stickers and posters. The aim has been to present succinctly the signs and symptoms of TB and leprosy, and the availability of treatment at health posts and clinics. Leprosy and TB NGOs assist the GoB in certain specified districts in the country, under a Memorandum of Understanding signed in 1994. These NGOs have developed their own

Correspondence to: R. P. Croft, 70 Culver Lane, Reading RG6 1DY, UK 
materials and methods of health education, including use of radio, slide shows, cinema slides, posters, stickers, handbills, drama and puppet shows. Again, the content has focussed on the signs and symptoms of disease and availability of treatment.

However, the authors could find no publications relating to the knowledge, attitudes and practice of the community towards leprosy and TB in Bangladesh, or of the effectiveness of mass health education. It is the authors' experience that prejudice against leprosy and TB sufferers is quite high in the country, and that there is much ignorance about the cause and treatability of these two diseases. Anecdotal evidence from colleagues working in different locations supports this view. Since Bangladesh is geographically close and culturally quite similar to India, a review of some of the studies carried out there may be relevant, as well as further afield.

In a large study carried out in 1995 in two Indian states, Raju and Kopparty ${ }^{1}$ found moderately high levels of knowledge about leprosy but surprisingly negative attitudes. About $50 \%$ of respondents from Andhra Pradesh had a 'high' knowledge level, 35\% in Orissa. However, almost all the subjects from Orissa (569/599, 95\%) had a negative attitude towards leprosy, and $75 \%$ from Andhra Pradesh. In Mangalore, southern India, only $15 \%$ of community members knew the early signs of leprosy, and $60 \%$ felt it was necessary to segregate patients. ${ }^{2}$ This study was carried out in 1985. In another survey in 1975 in Chingleput, Ramu and others found that $84 \%$ of community members thought that leprosy was caused by the 'malefic influence of stars', and none of their respondents was prepared to marry into a family with leprosy in it. ${ }^{3}$ In another study carried out in Myanmar (Burma), knowledge about leprosy was generally poor, with significant levels of stigma present in the community. ${ }^{4}$ Even in the United States, considerable stigma has been found to exist. Gussow and Tracy, in a survey carried out in 1972, found that $60 \%$ of non-professional workers in the department of Public Health in California thought that leprosy sufferers should be isolated, and $68 \%$ thought it was not acceptable for leprosy sufferers to work around other people. ${ }^{5}$

Publications describing community knowledge, attitudes and practices relating to TB are very few indeed, and the authors could find none relating to the Indian subcontinent. However, the available literature suggests that it shares some characteristics with leprosy. Ebner (1968) asked respondents in Baton Rouge, Louisiana, near the leprosy centre at Carville, 'what diseases stand out in your mind as being the worst or least desirable?'. The answers showed that syphilis, mental illness, TB and leprosy were at the top of the list. ${ }^{6}$ Barker, in analysis of a sociological study, concluded that 'the popular concept of leprosy is almost identical with that of tuberculosis'. ${ }^{7}$ In Birmingham, England, Bakhshi and Ali found that $94 \%$ of TB patients did not suspect TB when the symptoms first appeared, and that knowledge about the signs and symptoms of the disease was lower among the non-white, largely Asian, community. ${ }^{8}$

Danish Bangladesh Leprosy Mission (DBLM) is a large NGO administered by The Leprosy Mission operating in four districts of northern Bangladesh for the control of leprosy and TB in partnership with the Government. We decided to conduct a small Knowledge, Attitude and Practice (KAP) study to try and understand better what the opinions of the rural community are, and to compare the knowledge, attitudes and practices on leprosy and TB among two areas, one which had received regular and intensive health education, and one which had not.

\section{Materials and methods}

The study was carried out by the Danish Bangladesh Leprosy Mission (DBLM) in north-west 
Bangladesh in September 1997. DBLM is responsible to the Government of Bangladesh for administering a leprosy and TB control programme covering the two north-western districts of Thakurgaon and Panchagar. The leprosy project started in 1978 and covers an area known to have the highest prevalence of leprosy in the country (up to 5/1000 in NW Bangladesh). ${ }^{9}$ The leprosy case detection rate in 1996 was $4 \cdot 1$ per 10,000 . The TB control programme started in $1994 .^{10}$ The incidence of new sputum smear positive tuberculosis (TB) is estimated to be $1 \cdot 1 / 1000,{ }^{11}$ and in 1996 the TB case detection rate was 4.0 per 10,000 . The population according to the 1991 Census is $1,798,600$ and the area covered is $3213 \mathrm{~km}^{2}$.

\section{STUDY AREAS}

Two rural areas in Panchagar district were selected for the survey. Both areas are broadly similar, being populated by a majority Muslim community of small landowners and landless day labourers, with a few more major landowners. One of the areas, Pamoly Union, has had extensive health education coverage by DBLM staff over a period of 2-3 years. By contrast, the other area, Boroshoshi Union, has had hardly any health education coverage by DBLM staff, since it is geographically difficult to access. The Unions each have a population of about 20,000 .

THE SURVEY

A questionnaire was developed with the aim of assessing knowledge, attitudes and practice towards leprosy and TB. Two local Bangladeshis, one male and one female, one Muslim and one Hindu, were selected to carry out the survey. One was a DBLM Physiotechnician, the other a woman who had worked as a DBLM Leprosy Control Assistant. Neither of these workers had worked in the study area at any time. After fully discussing the questionnaire with them to ensure they clearly understood it, the two workers conducted a pilot study with the questionnaire. After feedback, the form was modified and a final version prepared for the survey. The questionnaire was kept deliberately short, since it is difficult to get the attention of busy householders for much longer than an hour.

Within each Union, a village was selected, and the interviewers chose a house near the centre of each village to start from. They then worked serially, going from house to house until 50 households had been covered in each village, giving a total of 100 interviews. The interviewers simply stated that they wanted to find out what the families thought about leprosy and TB, without explaining that they worked for DBLM, or 'Danish' as it is locally known. Instead of interviewing individuals, the interviewers requested that all the members of the household there at the time should be present for the interview. Most of the time the head of the household took a lead in responding to the interviewer, frequently consulting with other family members. We felt this was a reasonable approach, since in Bangladesh illnesses are rarely private and a sufferer would be expected to ask the views of other members of his or her household.

The survey was carried out over 2 separate weeks in September 1997. Each survey took 5 days in each Union to complete, doing 10 interviews of 40-50 min per day. After the survey, the questionnaires were analysed and the results entered into a simple database written using Epi-Info software. 
HEALTH EDUCATION PROGRAMME

The Health Education programmes on the signs and symptoms of TB and availability of treatment had been conducted regularly in Pamoly Union over 2 years. These included a day/ night mass information programme run from a jeep using flip charts, a bullhorn loudspeaker and two locally developed slide series showing simple stories about leprosy and TB sufferers who receive successful treatment. The slide series had been shown five times in evening sessions over the 2 years, with an audience of several hundred each time. In addition, in 1995 all schools were visited and information given about both diseases. The local DBLM TB/ Leprosy Control Assistant (TLCA) had also been active in conducting contact surveys and group health education activities in shops and bazaars. By contrast, Boroshoshi Union had received only one mass day/night information programme during the same period. The local TLCA responsible for Boroshoshi Union has visited the area minimally, for geographical reasons.

\section{STATISTICAL METHODS}

Results were analysed using the Chi squared $\left(\chi^{2}\right)$ test to indicate the strength of the evidence against the null hypothesis in Epi Info software ver. 6.01. Independent sample $t$-tests for the comparisons of means were carried out using SPSS for Windows, ver. 6.1.

\section{Results}

THE TWO SELECTED AREAS

In Boroshoshi Union, there was a mean of 3.3 people living in each household, and 2.6 in Pamoly (difference significant, $p<0 \cdot 05$ ). The mean area of land owned by the households was higher in Pamoly ( $2 \cdot 1$ hectares) than Boroshoshi $(0 \cdot 7$ hectares; $p=0 \cdot 064, t$-test $)$ with a correspondingly significantly higher monthly income of Tala 2450 (US\$61) versus Taka 1550 (US\$39) $(p<0.05, t$-test). The skew was mainly due to a small number of rich landowners in Pamoly (eight with $>4$ hectares). The proportion of landless households did not differ significantly (Pamoly 38\%, Boroshoshi 28\%, $p=0.39$ ), in fact with a higher number in the correspondingly 'richer' Pamoly. The religious makeup of the two communities did not differ significantly, with $78 \%$ Muslim in Boroshoshi and $74 \%$ Muslim in Pamoly, the remainder being Hindu ( $p=0 \cdot 64)$.

KNOWLEDGE ABOUT LEPROSY AND TB

Knowledge levels about both diseases were low in the 'unreached' community in Boroshoshi. Interestingly, knowledge about leprosy appears to be even lower than about TB-the question What do you know about leprosy? shows very few mentioned key words such as 'patch' (16\%), 'sensation loss' (0), or even 'deformity' $(6 \%)$, with $62 \%$ returning a 'don't know'. By contrast, to the question What do you know about TB?, 44\% replied 'cough' for TB and $48 \%$, blood in the sputum. Knowledge about where the diseases come from was similarly poor for both, with $96 \%$ returning 'don't know' for leprosy and $80 \%$ for TB. Sixty-four percent thought that ordinary people could get leprosy, and $46 \%$ thought leprosy was curable, $58 \%$ for TB. However, in Pamoly, where there has been a high level of community education, 
knowledge about both diseases was significantly higher. The key words 'patch' and 'sensation loss' were mentioned by $90 \%$ and $50 \%$, respectively, with respect to leprosy, and 'cough' and 'blood in sputum' by $90 \%$ and $94 \%$ with respect to TB. Knowledge that both diseases were curable was very high (leprosy, 94\%; TB 95\%), as was the knowledge that treatment was freely available (leprosy, 96\%; TB, 78\%). However, the majority were still unclear about the cause of leprosy (don't know, 84\%) and TB (don't know, 64\%); a very low proportion cited 'germs' as a cause of leprosy (4\%) and TB (2\%). There was a misconception about smoking and TB, with about a fifth of the respondents reporting smoking as a cause of TB.

All of the statistical differences between Pamoly and Boroshoshi and TB are significant with a $p$ value of $<0.05$ ( $\chi^{2}$ test).

\section{ATTITUDES TOWARDS LEPROSY AND TB}

Table 1 shows that there are alarmingly high levels of stigma attached to both diseases, with prejudice towards TB level being on a par with leprosy. In all, 74-76\% of families would not allow a leprosy or TB sufferer to eat with the family, and would not buy goods from a shopkeeper who was a sufferer. Anecdotally, several families reacted with anger when the suggestion was made that they might buy goods from a diseased shopkeeper. Around $50 \%$ of families would not share a tubewell with a neighbour if his son had TB or leprosy, and a very high $94 \%$ of families stated that they would not permit their son to marry a girl with cured leprosy, $88 \%$ for a girl with cured TB.

Once again, a markedly lower level of prejudice was demonstrated in the community in Pamoly, with between $18 \%$ and $28 \%$ of households giving negative, prejudicial answers to the four questions.

PRACTICE ABOUT LEPROSY AND TB

Table 2 shows a reliance on private qualified 'MBBS' doctors and village doctors (informally trained allopathic practitioners) rather than leprosy and TB clinics in the unreached Boroshoshi community, significantly reversed in Pamoly. Similarly, knowledge about DBLM, its provision of free service and knowledge of its clinic location was very low in Boroshoshi (88-92\% 'don't know' to these three questions), while $72 \%$ of respondents had heard about DBLM in Pamoly.

\section{Discussion}

This small study shows high levels of ignorance and prejudice towards leprosy and TB, both of which are endemic in Bangladesh and the current focus of control strategies. We had thought that impoverishment was the principal social consequence of infection by TB. ${ }^{10,12}$ However, this survey shows that levels of knowledge about TB, while higher than for leprosy, are still inadequate; and that levels of prejudice are of about the same level, as was found in the USA. ${ }^{6,7}$ These findings are in line with the community studies carried out in India and Myanmar mentioned in the Introduction, which also found low levels of knowledge about leprosy in the community and high levels of expressed prejudice towards sufferers. While it 
Table 1. Attitudes towards TB and leprosy

\begin{tabular}{|c|c|c|c|c|c|c|c|}
\hline \multirow[b]{2}{*}{ Leprosy related questions } & \multirow[b]{2}{*}{ Answer } & \multicolumn{2}{|c|}{ Responses } & \multirow[b]{2}{*}{$\mathrm{TB}$ related questions } & \multirow[b]{2}{*}{ Answer } & \multicolumn{2}{|c|}{ Responses } \\
\hline & & $\begin{array}{l}\text { Boroshoshi } \\
\quad n(\%)\end{array}$ & $\begin{array}{l}\text { Pamoly } \\
n(\%)\end{array}$ & & & $\begin{array}{l}\text { Boroshoshi } \\
\quad n(\%)\end{array}$ & $\begin{array}{c}\text { Pamoly } \\
n(\%)\end{array}$ \\
\hline $\begin{array}{l}\text { Can a leprosy sufferer eat with } \\
\text { his or her family? }\end{array}$ & $\begin{array}{l}\text { Yes } \\
\text { No } \\
\text { Don't know }\end{array}$ & $\begin{array}{c}9(18) \\
38(76) \\
3(6) \\
\chi^{2}=28 \cdot 3 \\
\text { degrees of }\end{array}$ & $\begin{array}{c}35(70) \\
15(30) \\
0(0) \\
<0 \cdot 05 \\
\text { edom }=2\end{array}$ & $\begin{array}{l}\text { Can a TB sufferer eat with his } \\
\text { or her family? }\end{array}$ & $\begin{array}{l}\text { Yes } \\
\text { No } \\
\text { Don't know }\end{array}$ & $\begin{array}{l}10(20) \\
27(74) \\
3(6) \\
\chi^{2}=24 \cdot 4 \\
\text { degrees of }\end{array}$ & $\begin{array}{c}38(74) \\
12(24) \\
0(0) \\
<0 \cdot 05, \\
\text { dom }=2\end{array}$ \\
\hline $\begin{array}{l}\text { If a shopkeeper had leprosy, } \\
\text { would you buy from his shop? }\end{array}$ & $\begin{array}{l}\text { Yes } \\
\text { No } \\
\text { Don't know }\end{array}$ & $\begin{array}{c}12(24) \\
38(76) \\
0(0) \\
\chi^{2}=29 \cdot 2 \\
\text { degrees of }\end{array}$ & $\begin{array}{c}39(78) \\
11(22) \\
0(0) \\
<0 \cdot 05 \\
\text { edom }=2\end{array}$ & $\begin{array}{l}\text { If a shopkeeper had TB, would } \\
\text { you buy from his shop? }\end{array}$ & $\begin{array}{l}\text { Yes } \\
\text { No } \\
\text { Don't know }\end{array}$ & $\begin{array}{c}11(22) \\
37(74) \\
2(4) \\
\chi^{2}=29 \cdot 6 \\
\text { degrees of }\end{array}$ & $\begin{array}{c}38(76) \\
12(24) \\
0(0) \\
<0 \cdot 05, \\
\text { edom }=2\end{array}$ \\
\hline $\begin{array}{l}\text { Would you let your neighbour } \\
\text { use your tubewell if his son had } \\
\text { leprosy? }\end{array}$ & $\begin{array}{l}\text { Yes } \\
\text { No } \\
\text { Don't know }\end{array}$ & $\begin{array}{l}22(44) \\
27(54) \\
1(2) \\
\chi^{2}=15 \cdot 7 \\
\text { degrees of }\end{array}$ & $\begin{array}{c}41(82) \\
9(18) \\
0(0) \\
<0 \cdot 05 \\
\text { edom }=2\end{array}$ & $\begin{array}{l}\text { Would you let your neighbour } \\
\text { use your tubewell if his son had } \\
\text { TB? }\end{array}$ & $\begin{array}{l}\text { Yes } \\
\text { No } \\
\text { Don't know }\end{array}$ & $\begin{array}{l}25(50) \\
23(46) \\
2(4) \\
\chi^{2}=9 \cdot 30 \\
\text { degrees of }\end{array}$ & $\begin{array}{c}39(78) \\
11(22) \\
0(0) \\
0 \cdot 05, \\
\text { edom }=2\end{array}$ \\
\hline $\begin{array}{l}\text { Would you let your son marry a } \\
\text { girl with cured leprosy? }\end{array}$ & $\begin{array}{l}\text { Yes } \\
\text { No }\end{array}$ & \multicolumn{2}{|c|}{$\chi^{2}=45 \cdot 78, p<0.05$} & $\begin{array}{l}\text { Would you let your son marry a } \\
\text { girl with cured TB? }\end{array}$ & $\begin{array}{l}\text { Don't know } \\
\text { Yes } \\
\text { No } \\
\text { degrees of } \mathrm{fr}\end{array}$ & $\begin{array}{c}4(8) \\
4(8) \\
44(88) \\
\chi^{2}=45 \cdot 1 \\
m=2\end{array}$ & $\begin{array}{c}0(0) \\
36(72) \\
14(28) \\
<0.05,\end{array}$ \\
\hline
\end{tabular}


Table 2. Practice about leprosy and TB

\begin{tabular}{|c|c|c|c|c|c|c|c|}
\hline \multirow[b]{2}{*}{ Leprosy related question } & \multirow[b]{2}{*}{ Answer } & \multicolumn{2}{|c|}{ Responses } & \multirow[b]{2}{*}{$\mathrm{TB}$ related question } & \multirow[b]{2}{*}{ Answer } & \multicolumn{2}{|c|}{ Responses } \\
\hline & & $\begin{array}{l}\text { Boroshoshi } \\
\quad n(\%)\end{array}$ & $\begin{array}{l}\text { Pamoly } \\
n(\%)\end{array}$ & & & $\begin{array}{l}\text { Boroshoshi } \\
n(\%)\end{array}$ & $\begin{array}{c}\text { Pamoly } \\
n(\%)\end{array}$ \\
\hline $\begin{array}{l}\text { What would you do if you } \\
\text { thought you might have leprosy }\end{array}$ & $\begin{array}{l}\text { Lep. Clinic } \\
\text { Private Dr. } \\
\text { Village Dr. } \\
\text { Trad. Healer } \\
\text { Don't know }\end{array}$ & $\begin{array}{c}9(18) \\
17(34) \\
12(26) \\
6(12) \\
6(12) \\
\chi^{2}=30 \cdot 08 \\
\text { degrees o }\end{array}$ & $\begin{array}{c}30(60) \\
9(18) \\
1(2) \\
10(20) \\
0(0) \\
<0 \cdot 05, \\
\text { eedom }=4\end{array}$ & $\begin{array}{l}\text { What would you do if you } \\
\text { thought you might have TB? }\end{array}$ & $\begin{array}{l}\text { TB. Clinic } \\
\text { Private Dr. } \\
\text { Village Dr. }^{\mathrm{b}} \\
\text { Trad. Healer } \\
\text { Don't know }\end{array}$ & $\begin{array}{c}11(22) \\
20(40) \\
15(30) \\
0(0) \\
4(8) \\
\chi^{2}=32 \cdot 36, \\
\text { degrees of }\end{array}$ & $\begin{array}{c}37(74) \\
11(22) \\
0(0) \\
0(0) \\
2(4) \\
0 \cdot 05, \\
\text { edom }=4\end{array}$ \\
\hline
\end{tabular}

a Private registered 'MB BS' doctor

${ }^{\mathrm{b}}$ Village doctor: informally trained village medical practitioner.

${ }^{\mathrm{c}}$ Traditional healer. 
may be true that north Bangladesh is particularly poor in terms of knowledge and attitudes towards these two diseases, the rest of the country is unlikely to be very different.

Reassuringly, it appears that the area with the well-conducted community health education campaign showed a higher level of knowledge and more favourable attitudes. At least in Bangladesh, this should be a message of importance to both the GoB and NGOs as they plan their strategy for control of these two diseases. Since both diseases have an important social dimension, it is crucial that the community understands the cause and treatability of these two infections, both so that possible cases can present to a diagnostic facility without hindrance, and so that people receiving treatment can continue to live and be fully integrated into the community. It shows that health education can make a large difference to community attitudes towards these two diseases, thus significantly reducing the suffering associated with them. It must be easier to have leprosy or TB in Pamoly than in Boroshoshi.

However, there were indications that attitudes still lag behind knowledge, as has been found elsewhere. ${ }^{1}$ About a quarter of respondents in the area that had received health education still believed that leprosy or TB sufferers should not eat with the family members, although the majority ( $>90 \%$ ) knew that both diseases were curable. A similar proportion would not buy from a diseased shopkeeper, share a tubewell or marry into a family with leprosy or TB. Changing prejudicial attitudes on any subject is an enormous challenge in any culture. It is probably true that the 'final change' will not come about until it is clear by personal, local community observation that both diseases, once treated, present no risk to the community. Jopling in his review on leprosy stigma ${ }^{13}$ stresses that the availability of MDT is the key to reduction in stigma. Therefore, making it easy and possible for sufferers to receive early and effective treatment is a necessary adjunct to any campaign of health education.

As a project, DBLM felt that in general this study provided confirmation that its health education programme was proceeding in the right direction, while recognizing that there are 'black holes' where the programme has, for one reason or another, not been sufficiently intense to bring about a reversal of knowledge and attitudes, as in Boroshoshi. These areas need identification and targeting. DBLM has an active health education committee composed of senior staff involved in field work and disability prevention, whose brief is to continue to develop ways of bringing the message that 'leprosy and TB are curable' to the community.

This is a small study, also limited because the two communities differed significantly in income and land ownership, while being comparable in religious makeup. The study design (a descriptive cross-sectional study), strictly speaking, did not enable us directly to assess the effectiveness of the campaign, since for this objective it would have been necessary to assess knowledge, attitudes and practices in the same area before and after the implementation of a health education programme. Boroshoshi Union is geographically isolated, and for this reason received little health education about leprosy and TB from DBLM. It may be that its relative social isolation within the locality is part of the explanation of why knowledge about the diseases was so poor, and attitudes so negative. It would be very valuable to follow up this study with another, identical survey carried out on the same families in Boroshoshi in a year or two's time, after the area has been targeted for health education.

However, the study does suggest that a well-executed campaign of health education can dramatically change levels of knowledge about leprosy and $\mathrm{TB}$, and reverse prejudicial attitudes.

In summary, this study shows high levels of knowledge and more favourable attitudes towards leprosy and TB in an area that had received intensive health education. In contrast, 
there were very low levels of knowledge and unfavourable attitudes in a comparable area that had not had health education activities.

\section{Acknowledgement}

The authors are grateful to Dr Wong Mee Lian of the Department of Community, Occupational and Family Medicine at the National University of Singapore for her inspiration to carry out this study, and critical help in reviewing the paper.

\section{References}

${ }^{1}$ Raju MS, Kopparty SNM. Impact of knowledge on the attitude towards leprosy patients: a community study. Ind $J$ Lepr, 1995; 67: 259-272.

2 Shetty JN, Shivaswamy SS, Shirwadkar PS. Knowledge, attitude and practices of the community and patients regarding leprosy in Mangalore-a study. Ind J Lepr 1985; 57: 613-619.

3 Ramu G, Dwivedi MP, Iyer CGS. Social reaction to leprosy in a rural population in Chingleput district (Tamil Nadu). Lepr India, 1975; 47: 156-169.

${ }^{4}$ Myint T, Thet AT, Htoon MT, Win M. A comparative KAP study of leprosy patients and members of the community in Hlaing and Laung-Lon townships. Ind J Lepr, 1992; 64: 313-324.

${ }^{5}$ Gussow Z, Tracy GS. The phenomenon of leprosy stigma in the continental United States. Lepr Rev, $1972 ; 43$ : 85-93.

${ }^{6}$ Ebner JD. Community knowledge and attitudes about leprosy: a social-psychological study of the degree of stigmatisation of a chronic disease. MA thesis, Department of Sociology, Louisiana State University, Baton Rouge (quoted in Gussow and Tracy ${ }^{5}$ ).

7 Barker DS. Concepts of disabilities. Personnel and Guidance Journal, 1964; 43: 371 (quoted in Gussow and Tracy $^{5}$ ).

${ }^{8}$ Bakshi SS, Ali S. Knowledge, attitude and behaviour of TB patients. J Public Health Med, 1995; 17: $343-348$.

9 Richardus JH, Croft RP. Estimating the size of the leprosy problem: the Bangladesh experience. Lepr Rev, 1995; 66: $158-164$.

${ }^{10}$ Croft RA, Croft RP. Tuberculosis control is good for established leprosy programmes. Lepr Rev, 1996; 68: 139146.

11 Weyer K. Tuberculosis in Bangladesh, 1996. Report prepared for the Bangladesh TB Review, November 1997 (unpublished).

12 Croft RA, Croft RP. Expenditure and loss of income by tuberculosis patients before reaching effective treatment in Bangladesh. Int J Tuberc Lung Dis, 1998; 2: 252-254.

13 Jopling WH. Leprosy stigma (Editorial). Lepr Rev, 1991; 62: 1-12. 